4 Deichmann WB, Gerarde HW. Toxicology of drugs and chemicals. New York: Academic Press, 1969.

5 Ellenhorn MJ, Barreloux DG. Metals and related compounds. In: Medical toxicology-diagnosis and treatmen of human poisoning. New York, Elsevier, 1988:1057-8.

6 Gosselin RE, Smith RP, Hodge HC. Clinical toxicology of commercial products. Baltimore: Williams \& Wilkins, 1984.

7 Dreisbach RH, Robertson WO. Handbook of poisoning: prevention, diagnosis and treatment. California: Lange

8 Middleton SJ, Jacyna M, McClaren D, Robinson R Thomas HC. Haemorrhagic pancreatitis-a cause of death in severe potassium permanganate poisoning. Postgrad in severe potassium
9 Kochhar R, Das K, Mehta SK. Potassium permanganate induced oesophageal stricture. Hum Toxicol 1986;5:393-4.

10 Dagli AJ, Golden D, Finkel M, Austin E. Pyloric stenosis following ingestion of potassium permanganate. Am J Dig Dis 1973; 18:1091-4.

11 Lustig S, Pitlik SD, Rosenfeld JB. Liver damage in acute self-induced hypermanganemia. Arch Intern Med 1982, 142:405-6.

12 Mahomedy MC, Mahomedy YH, Canham PA, Downing JW, Jeal DE. Methaemoglobinaemia following treatment dispensed by witch doctors. Two cases of potassium dispensed by witch doctors. Two cases of potassium

13 Southwood T, Lamb CM, Freeman J. Ingestion of potassium permanganate crystals by a three year old boy. Med J Aust 1987;146:639-40.

\title{
Inadvertent intracranial insertion of a nasogastric tube in a non-trauma patient
}

\author{
R M Freij, S T H Mullett
}

\begin{abstract}
Complications following nasogastric intubation in patients with basal skull fractures are well documented. This report is of a rare cause of inadvertent intracranial placement of a nasogastric (NG) tube in a non-trauma patient. The patient subsequently died. The use of NG tubes, their place in airway management, and lessons to be learned from this case are discussed. (f Accid Emerg Med 1997;14:45-47)
\end{abstract}

Keywords: nasogastric tube; aspiration; airway; frontoethmoidal defect

\section{Case report}

A 59 year female patient with a history of known epilepsy presented to our accident and emergency (A\&E) department in status epilepticus of six hours' duration. The fit was terminated on arrival by administering intravenous diazepam. She was resuscitated with high flow
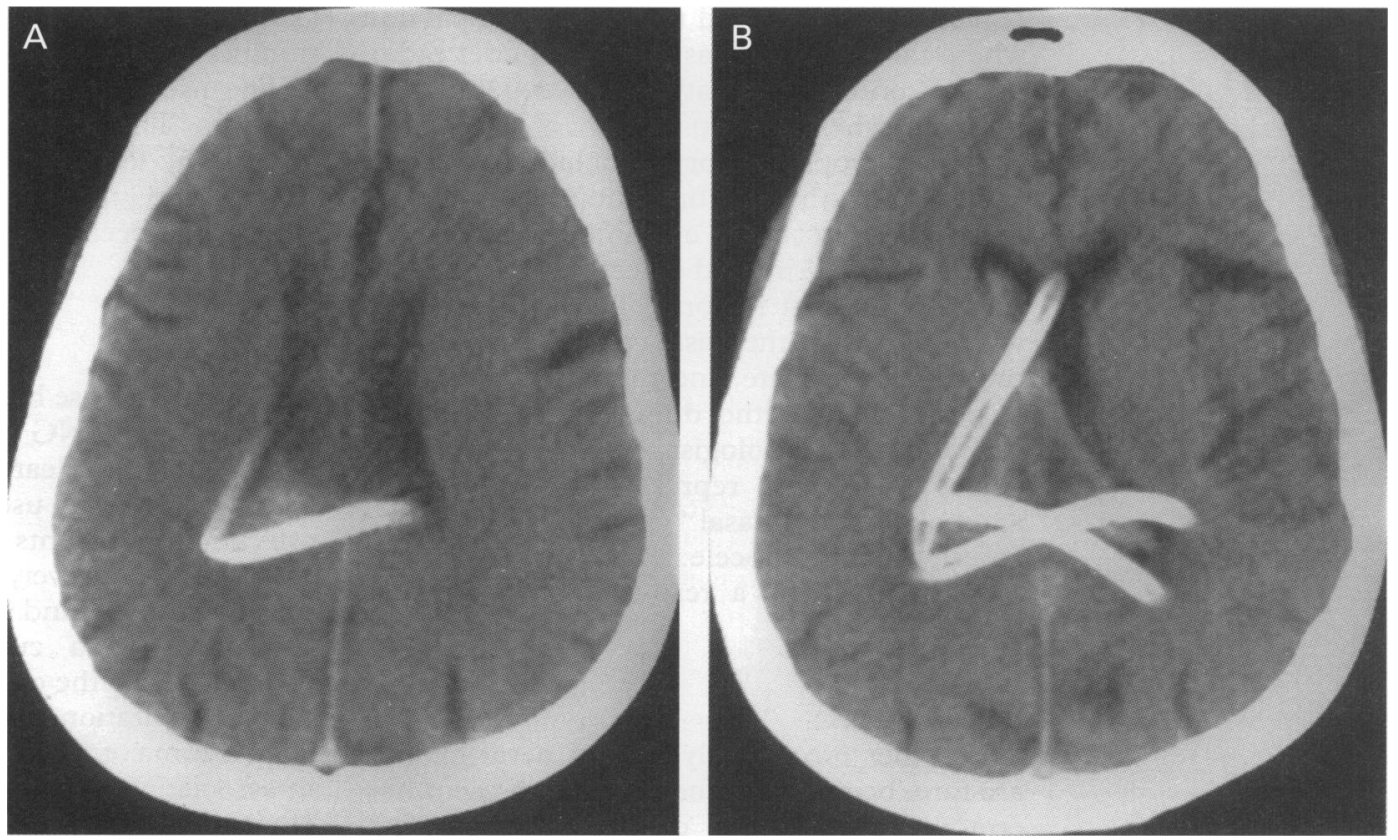

Figure 1 Computerised tomography scan showing the intracranial placement of the nasogastric tube.

oxygen, an oropharyngeal airway was inserted, and intravenous fluids were given. The history obtained from her husband was of several hours vomiting before the fit, but no history of any febrile illness or upper respiratory tract symptoms. She had been epileptic for 12 years, and despite taking vigabatrin (Sabril) and sodium valproate was poorly controlled. Of relevance in her past medical history was that she had suffered from an episode of pneumococcal meningitis before the start of her epilepsy.

On examination she was pyrexial $\left(38.4^{\circ} \mathrm{C}\right)$ with a tachycardia of 130 beats/min. There was decreased air entry to the right lung base, consistent with aspiration, later confirmed by chest radiograph. Her Glasgow coma score was between 6 and 10 . Further examination revealed no other abnormalities.

She was nursed in the recovery position. To reduce the risk of further aspiration the insertion of a nasogastric tube (NG) was

Department of Accident and Emergency Medicine, Central Middlesex Hospital, Acton Lane, Park Royal, London NW10 7NS

R M Freij

S T H Mullett

Correspondence to: R M Freij FRCS, Registrar in Accident and Emergency Medicine. e-mail

101453.2323@;

compuserve.com 


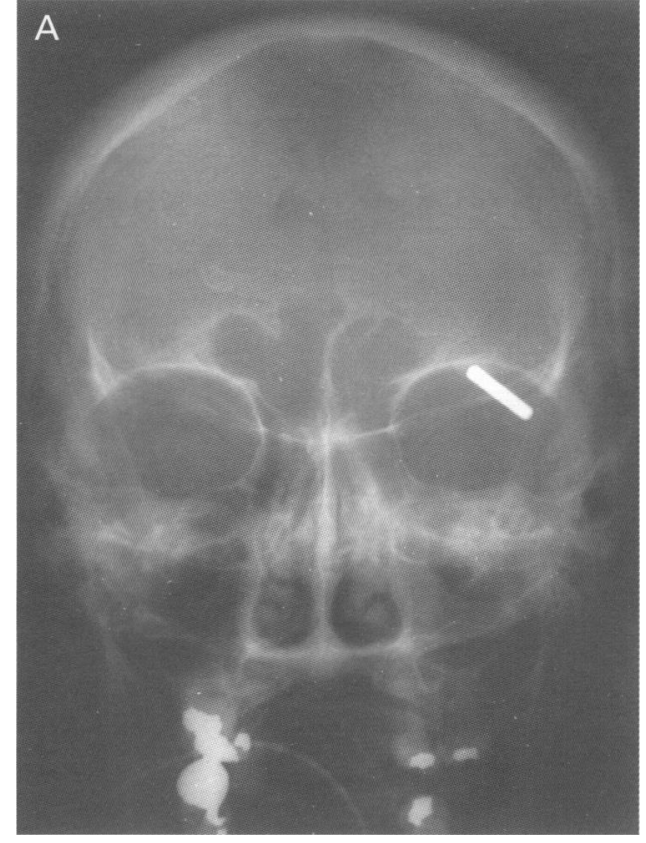

proposed. This was performed in accordance with recognised practice. ${ }^{1}$ Three attempts at insertion were made, each of them producing blood stained fluid. When the fluid was aspirated and tested using litmus paper there was no colour change. The tube was left in position after the third insertion as the fluid was assumed to be blood stained nasal secretions resulting from traumatic intubation.

Although the resuscitation was successful in terminating the fit, the patient remained deeply unconscious. In view of this, and the past history of meningitis, computerised tomography was undertaken. It was reported as showing an intraventricular shunt (fig $1, \mathrm{~A}$ and B). Her husband, however, had no recollection of any previous neurosurgery. Subsequent plain radiographs of the skull showed that the NG tube had passed through the skull base and was located intracranially (fig 2, A and B). The patient was transferred to a neurosurgical unit where the NG tube was removed under radiological control. The patient subsequently died from overwhelming sepsis.

The necropsy report concluded that the causes of death were bronchopneumonia and meningitis. On careful examination of the skull base, a smooth rimmed defect was noted in the fronto-ethmoidal region. This communicated with the roof of the nasal cavity, just lateral to the cribriform plate, and measured $8 \times 5 \mathrm{~mm}$. A perforation in the dura at that point was noted. The pathologist suggested that the defect may have represented a congenital anomaly called a nasal "glioma", similar to an anterior encephalocele. Alternatively it may have occurred as a result of previous head trauma.

\section{Discussion}

The rather erroneously named nasal gliomas are rare, benign, and thought to represent heterotopic brain tissue displaced during fetal development. ${ }^{2}$ They usually present as intra-

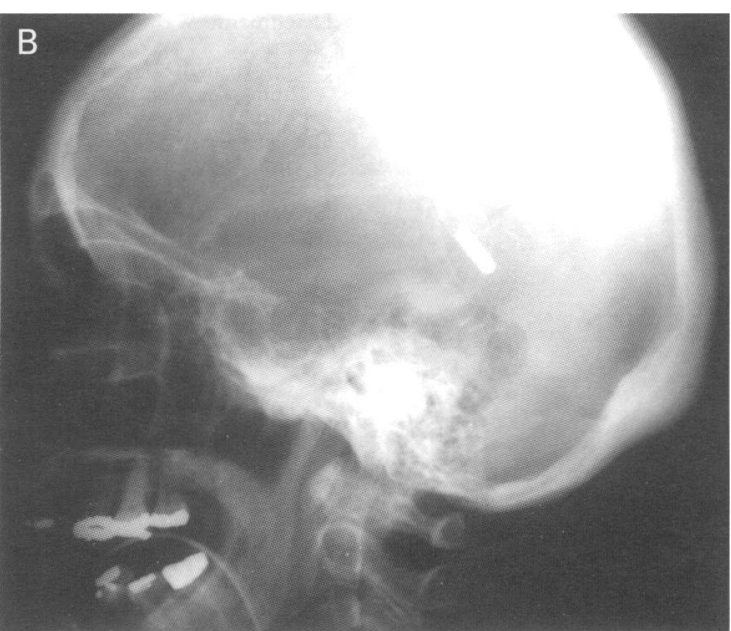

Figure 2 Plain skull radiographs; the nasogastric tube is clearly visible.

nasal masses in infants and children, and are commoner in South East Asia, our patient originating from that area (Branfoot AC, personal communication). However, they may occasionally persist as a small intracranial defect, visible only on magnetic resonance imaging. $^{3}$

We are aware of only one case report of inadvertent intracranial placement of an NG tube in an adult non-trauma patient. ${ }^{4}$ That case differed from ours, in that the patient survived, and it was only postulated that the cribriform plate had been thinned by a recent episode of sinusitis, precipitating the complication. There is a case report of intracranial placement of an NG tube in an infant without associated trauma. ${ }^{5}$

The advanced trauma life support course ${ }^{6}$ recommends that NG tubes should not be inserted where there is the possibility of a basal skull fracture, and this is borne out by a number of case reports. ${ }^{78}$

The use of NG tubes is under scrutiny in general. They may be a risk factor in aspiration, leading to anaerobic lung infections, ${ }^{9}$ and their use after gastrointestinal surgery has been questioned by some investigators. ${ }^{1011}$

\section{CONCLUSION}

Although this case highlights an extremely rare complication of NG tube insertion, certain lessons can be learned. NG tubes have traditionally been used to reduce the risk of aspiration in patients with altered level of consciousness. However, they carry risks - as this case illustrates - and should never be used as a substitute for a cuffed endotracheal tube, which remains the optimum choice for prevention of aspiration. We also feel that previous head trauma or a history of adult onset epilepsy in association with meningitis should alert the clinician to the possibility of a cranial defect. NG tubes should only be used with extreme 
care under these circumstances. The use of a precurved Silastic nasopharyngeal airway to facilitate insertion of the NG tube, as described by Bouzarth, ${ }^{12}$ may help prevent intracranial complications of this procedure.

1 Dyer I, Ashton WB. How to pass a nasogastric tube. $\mathrm{Br} \mathrm{J}$ Hosp Med 1991;45:45-6.

2 Azumi N, Matsuno T, Tateyama M, Inoue K. So called nasal glioma. Acta Pathol Jpn 1994;34:215-20.

3 Braun M, Boman F, Hascoet JM. Brain tissue heterotropia in the nasopharynx. Contribution of MRI to assessment of extension. J Neuroradiol 1992;19:68-74.

4 Glasser SA, Garfinkle W, Scanlon M. Intracranial complication during insertion of a nasogastric tube. Am J Neuroradiol 1990;11:1170

5 van den Anker JN, Baerts W, Quak JME, Robben SGF,
Meradji N. Iatrogenic perforation of the lamina cribrosa by nasogastric tube in an infant. Pediatr Radiol 1992;22:545-6.

6 Committee on Trauma American College of Surgeons. Advanced Trauma Life Support. Core course, 1993.

7 Sacks AD. Intracranial placement of a nasogastric tube after complex craniofacial trauma. Ear Nose Throat J 1993;72: 800-2.

8 Katz MI, Faibel M. Inadvertent intracranial placement of a nasogastric tube?. Am J Roentgenol 1994;163:222.

9 Vincent MT, Goldman BS. Anaerobic lung infections. Am Fam Physician 1994;49:1815-20.

10 Schwartz CI, Heyman AS, Rao AC. Prophylactic nasogastric tube decompression: is its use justified? South Med J tric tube decomp

11 Cheatham ML, Chapman WC, Key SP, Sawyer SJL. A meta-analysis of selective versus routine nasogastric decompression after elective laparotomy. Ann Surg 1995; 221:469-76.

12 Bouzarth W. Intracranial nasogastric tube insertion. J Trauma 1978;18:818-9.

\title{
Traumatic asphyxia in children
}

\author{
Gregor Campbell-Hewson, Conor V Egleston, Andrew R Cope
}

\begin{abstract}
Two cases of traumatic asphyxia in young children are reported. The first was a 2 year old child run over at low speed by the front wheels of a delivery van. He made an uncomplicated recovery. The second child was pinned to the floor by an empty chest of drawers in an unwitnessed accident. He was discovered in cardiac arrest and resuscitation was unsuccessful. The outcome following traumatic asphyxia is a product of duration of compression and the weight involved. Considerable weight can be tolerated for a short period, whereas a comparatively modest weight applied for a longer period may result in death.

(F Accid Emerg Med 1997;14:47-49)
\end{abstract}

Keywords; children; crush asphyxia; traumatic asphyxia

\section{Accident and Emergency Department, Addenbrooke's Hospital, Cambridge G Campbell-Hewson C V Egleston}

Accident and Emergency, Peterborough District Hospital, Peterborough A R Cope

Correspondence to: Dr Gregor

Campbell-Hewson, Accident and Emergency Department, Addenbrooke's Hospital, Hills Road, Cambridge CB2 2QQ.

Accepted for publication 4 September 1996.
The syndrome of traumatic asphyxia has been reported regularly in medical publications since its initial description by D'Angers Ollivier following his observations on the cadavers of people trampled upon during crowd disturbances in Paris on Bastille day 1837. ${ }^{1}$ It has been defined as cervico-facial cyanosis, subconjunctival haemorrhage, and cutaneous petechial haemorrhages following thoraco-abdominal compression. ${ }^{2}$

It was recently brought to prominence by the Hillsborough Stadium disaster where the victims bore some of the stigmata of traumatic asphyxia, although there were marked differences in presentation and outcome. ${ }^{34}$

The purpose of this paper is to report two cases of traumatic asphyxia in young children which show important and contrasting features of the pathophysiology of this condition, and to review the relevant published reports.
Case 1

The patient, a healthy 2 year old boy, chased a ball onto a road. He fell and his torso was run over by the front wheel of a delivery van (Ford Transit, unladen weight $1533-2075 \mathrm{~kg}$ ). The van had been driving slowly and stopped before the back wheels had reached the child. $\mathrm{He}$ did not lose consciousness and remained motionless under the van on the instructions of his parents.

On arrival in accident and emergency (A\&E) he was alert but jittery. His blood pressure was $105 / 55$, pulse 115 , respiratory rate 18 , and he was well perfused. He complained of abdominal pain which was poorly localised. His facial appearance was striking, with cervicofacial cyanosis and swelling, widespread petechiae, and bilateral subconjunctival haemorrhages (figure). There were no marks of compression on the torso. On fundoscopy there were bilateral retinal haemorrhages and exudates. Otherwise neurological examination was normal. There were no fractures or other abnormalities on radiographs of the skull, cervical spine, or chest. A plain abdominal radiograph showed acute gastric dilatation. He was initially treated with oxygen, intravenous fluids, urinary catheterisation, and insertion of a nasogastric tube to decompress the stomach. Arterial blood gases, haematology, and biochemistry profiles were all normal. A further chest radiograph 18 hours after the accident was also normal. An ultrasound of the abdomen failed to show any abdominal injury. Clinically he made good progress, although his dramatic facial appearance persisted. He was discharged 8 days later, by which time his appearance had almost returned to normal with only the resolving subconjunctival haemorrhages remaining. The main reason for his prolonged inpatient stay was the development of a swinging pyrexia on day 4 caused by an urinary tract infection, presumably secondary to catheteri- 